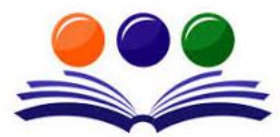

GRAND ACADEMIC PORTAL RESEARCH JOURNALS

\title{
SPIRITUAL INTELLIGENCE: A MEDIATING FACTOR IN REDUCING BURNOUT AMONGST MANAGERS
}

\author{
Anju Sharma, Prof D. M. Pestonjee
}

PhD Fellow, School of Petroleum Management, Pandit Deen Dayal Petroleum University (PDPU), India

Professor, School of Petroleum management, Pandit Deen Dayal Petroleum University (PDPU), India

\begin{abstract}
Human beings are the only beings in this universe that question the very basic existence of something by asking the "Why" question. An intelligence that allows an individual to find answers to these very basic questions of meaning and existence has to move beyond the realm of body and mind into the realm of consciousness and connection to the ultimate reality. This connection is possible only through the individual manifestation of this reality- the inner Self or Spirit. Such intelligence has been named as Spiritual Intelligence. Research studies have proven that managers working in people-professions that involve interaction and interface with people on an on-going basis are more prone to burnout as constant emotional demands made by the clients or team members can tire people out emotionally and mentally. As these managers are required to present a very amicable and present personality irrespective of their actual mental or emotional state, they gradually get exhausted. This paper deliberates upon this very important but usually neglected side of the contemporary managers.
\end{abstract}

Keywords: Modern organizations, Spiritual intelligence, Stress management, Leadership, Bhagavad Geeta

\section{INTRODUCTION}

The modern workplace environment has become very challenging in recent times. The employer-employee relationships have gone through sea-change at both, local well as global levels. This diversity in culture, nature, policies, and the very fluid dynamics of the international relationships have opened up many new issues and just like Pandora's Box, every day newer challenges are being faced by the new age managers. In this backdrop, the need of the hour is the individual manifestation of this reality- the inner Self or Spirit, which is the most important concern. The history of mankind has proved that human beings are the only beings in this universe that question the very basic existence of something by asking the "Why" question. An intelligence that allows an individual to find answers to these very basic questions of meaning and existence has to move beyond the realm of body and mind into the realm of consciousness and connection to the ultimate reality. This connection is possible only through the individual manifestation of this reality- the inner Self or Spirit. Such intelligence has been named as Spiritual Intelligence.

\section{RESEARCH OBJECTIVE}

Research studies have proven that managers working in people-professions that involve interaction and interface with people on an on-going basis are more prone to burnout as constant emotional demands made by the clients or team members can tire people out emotionally and mentally. As these managers are required to present a very amicable and present personality irrespective of their actual mental or emotional state, they gradually get exhausted. The pressures of time and performance-pressures in an atmosphere of fierce competition also induce deep psychological stress that culminates in Burnout. Burnout sets in a cycle of response in which the lack of psychological wellbeing starts affecting the physical health of an individual through several psychosomatic disorders. Physical discomfort and illness in turn become a source of negative emotions that further vitiates physical and mental health. The objective of this paper is to develop a conceptual background of the mediating factors that can reduce burnout.

\section{METHODOLOGY}

This paper discusses some of the descriptive research design and the arguments are based on the available secondary resources. Some of the important areas of arguments are discussed as under: 


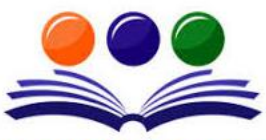

GRAND ACADEMIC PORTAL RESEARCH JOURNALS

\section{A GLOBAL JOURNAL OF HUMANITIES}

( ISSN - 2581-5857)

Impact Factor: SJIF - 5.171, IIFS - 5.125

\section{REVIEW OF LITERATURE}

While on one hand, the Spirit tends to be overlooked in finding solutions at work, there is enough evidence that a large number of people suffer from stress at work. According to Robbins (2003) an opportunity, demand, constraint, threat, or challenge can create stress for an individual when the effect of the event is uncertain and important. In 1999, Maxon estimated through a study that workplace stress costs US employers an estimated 200 billion dollars a year through absenteeism, decreased productivity, turnover, workers compensation claims and health insurance costs.

Stress arises primarily because of the difference between reality and expectation. Fredin and Nordin (2015) found in a study conducted in a Swedish public organization that organizational Role Stress hurts managers' ability to balance administrative responsibilities and operative leadership. Dr. Udai Pareek (1983), a pioneer in developing a measurement scale for organizational Role Stress stated that Burnout takes place when executives fail to cope with the stressful conditions. Dr. Udai Pareek identified ten components of Role Stress viz. Inter Role Distance (IRD), Role Stagnation (RS), Role Expectation Conflict (REC), Role Erosion (RE), Role Overload (RO), Role Isolation (RI), Personal Inadequacy (PI), Self role Distance (SRD), Resource Inadequacy (RIN) and Role Ambiguity (RA).

The accumulation of stress over time leads to burnout and this in turn may cause many health and personal issues. Maslach et al (2016) define that Burnout is a psychological syndrome emerging as a prolonged response to chronic interpersonal stressors on the job. The three key dimensions of this response are an overwhelming exhaustion, feelings of cynicism and detachment from the job, and a sense of ineffectiveness and lack of accomplishment. The significance of this three-dimensional model is that it places the individual stress experience within a social context and involves the person's conception of both self and others.

According to Sophia Kahill (1998) Depression which appears to be a response makes wrong effects on individuals' psychology and the symptoms are these: worry, feeling helpless, and loss of confidence. In several studies, stress has been found to exist at all levels of management through varying degrees. However, it was found by Tripathy (2002) that middle-level managers in the age group of 41 to 50 feel maximum burnout. Stress is inevitable at work and in life. It tends to lead to unhealthy consequences if left unmanaged. The incidence of high stress in workplaces is so widespread that an entire industry is thriving around it claiming to teach us ways to deal with stress or manage our stress for us. Some of them may just be quick-fix solutions touching very peripheral levels of our being while some may have a deeper impact.

A study by Sharma (2005) revealed that about 32\% of the total sample of mental health professionals felt that around $10 \%$ of the population is affected by the problem of burnout, followed by almost $20 \%$ stating that about $20 \%$ of people suffer from burnout in both government and private sectors. It is noteworthy that only less than $4 \%$ of the sample felt that burnout is present in less than $10 \%$ of the population. The results indicate overwhelming correspondence between stress and psychoneurosis/psychosis. All the mental health professionals (96.15\%) who responded to the questions were unanimous in their response that stress is a cause of psychoneurosis/psychosis.

\section{EMOTIONAL INTELLIGENCE VIS A VIS SPIRITUAL INTELLIGENCE}

Goleman (1996) said that emotional intelligence greatly affects the life of a person as a whole from life in the family, the work, to the interaction with his social environment. The researcher says mood coordination is the essence of good social relations. When a clever person adjusts to the mood of another individual or can empathize, the person will have a good emotional level and will more easily adjust in social and environmental relationships. Further, he explained that emotional intelligence is the more ability a person has in selfmotivating, resilience in the face of failure, controlling emotions and delaying satisfaction, and regulate the soul. Having high emotional intelligence can place emotions in the right portion, have satisfaction, and set the mood.

However, while Emotional Intelligence addresses behavior and mood, externally, the impact on the inner being is not felt much as the ego is still in control and the person has not aligned internally with the reality of life. Emotional Intelligence can hence, at best give short-term results as the ego fill continues to face challenges and responding in ways that tend to preserve the identity that it has created for itself but which may not be close to reality. Hence, there is bound to be inner unfulfillment till the ego is not dissolved or expanded to a level that its identity gets merged with a cosmic identity. The inner unfulfillment gets manifests in a lack of peace and satisfaction from one's life and resultant inner discord leading to mental illness and depression or just general discomfort caused by Burnout.

Spiritual Intelligence allows a person to expand their ego and transcend it to develop an awareness of true Self. As one does so, it takes over the qualities of the true self which is like truth, love, and bliss; leading to inner peace and fulfillment. Also, as a person aligns with the cosmic Self and realizes the existence of a transcendental reality, the faith in the goodness of things enables him to accept things with positivity.

Spiritual intelligence transcends the false self (ego) by being the true Self (soul). Therefore, in addition to experiencing the qualities of the soul, in the form of peace, joy, love, and compassion, the spiritual quotient also 


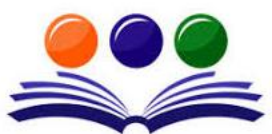

GRAND ACADEMIC PORTAL RESEARCH JOURNALS

\section{A GLOBAL JOURNAL OF HUMANITIES}

( ISSN - 2581-5857)

Impact Factor: SJIF - 5.171, IIFS - 5.125

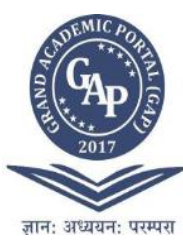

has access to all the capabilities of the soul, in the form of witnessing ego-less perception, ego-less motives, wisdom, intuition, integrity, inherent self-esteem, and creativity, resulting in top performance. Consequently, emotional quotient combined with spiritual quotient is more powerful than emotional quotient on its own, in the absence of spiritual quotient. Thus, the essential difference between emotional quotient and the spiritual quotient is the identity shift from ego to soul, which provides access not only to the qualities of the soul but also to the soul's capabilities.

Spiritual Intelligence can, hence, reduce the impact of stress on a person by allowing the person to deal with it effectively. Once the person can disassociate from the stressors through the awareness of self, the effect of these stressors is highly reduced. Therefore, while the stress is bound to remain, spiritually intelligent people are not likely to get burnt out.

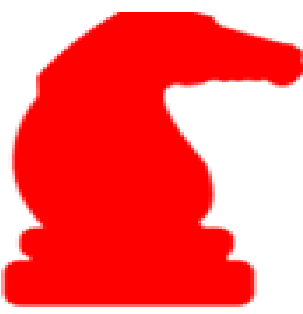

IQ

Figure 1: Three Dimensions of Leadership Three Dimensions of Leadership

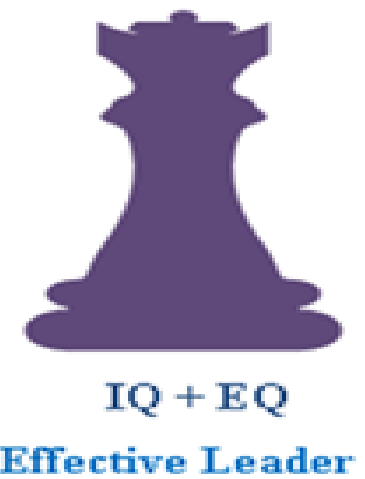

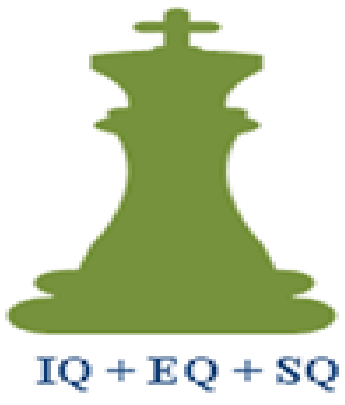

Blissful Leader

Robert A Emmons (2000) mentions that spirituality is a domain marked by a concern with the sacred and transcendental realities whereas spiritual intelligence is the potential to utilize the potential of spiritual information to facilitate problem-solving. It is a resource that can be used by individuals for decision making and better functional performance as well as to work out ways to understand and solve the problems of life. Spirituality is an experience of higher states of consciousness. Where the individual Self gets aligned with the transcendental self, it involves an individual's search for meaning in life, wholeness, peace, individuality, and harmony and is a state of being (Macquarrie, 1972).

When a person is spiritual, he /she is bound to possess spiritual Intelligence which is the application or operational aspect of Spirituality. Experience leads to the application of principles or application of principles leads to experience. The ultimate result is a peaceful and fulfilled co-existence and liberation from the negative consequences that undesired fruits of action may bring. 5000 years ago, Bhagwad Gita called it Karma Yoga where a person does his duty and carries out his purpose in life without worrying about the results. If the actions are well rooted in duty and goodness, the results are bound to be good and beneficial to the universe at large.

In verses, 51 to 53 of chapter 18, of Bhagwad Gita the following qualities of the spiritually intelligent people are described-

1) Those who are fully purified

2) Regulating the self by determination

3) Give up mundane pleasures of senses iv. castaway repulsion and obsession

4) Avoid materialistic persons

5) Moderate in eating

6) Controlled in body, mind, and speech

7) Always absorbed in the science of Yoga; detached from mundane

8) Relinquish lust, egotism, power, pride, anger, charity or donations

9) Peaceful without any sense of proprietorship

In addition to these, it lays down the following major principles of Spiritual Intelligence-

- Lord Krishna taught Arjuna that a leader should maintain equilibrium in all situations. He used the term "Stith Pragya" for this. This can be translated in English as "Steadfastness; or situated or unmoved consciousness'. Chapter 2 verses 54 to 59 of Bhagwad Gita describes the qualities of people who are Stith Pragya. "He whose mind is not shaken by adversity, who does not hanker after pleasures, and is free from attachment, fear, and anger (verse2. 56). The wisdom of such person remains established who has not 


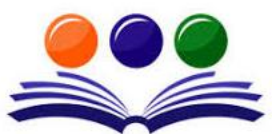

GRAND ACADEMIC PORTAL RESEARCH JOURNALS

attachment for anything anywhere, who neither welcomes nor rejects anything whatever good or bad when he comes across it(verse2.57).

- In chapter 3, Krishna describes Karmayog to Arjuna saying that he who controls the senses by the mind and engages his active organs in following his duty, without attachment, is by far superior. A person should therefore, perform his prescribed duty, for action is better than inaction. A man cannot even maintain his physical body without work. Hence a person should continuously strive for his purpose by carrying out his duty without attachment.

- In chapter 13, Sri Krishna describes the Gyan yoga describing it as a state when a man ceases to see different identities, which are due to different material bodies, he attains to the Brahman conception. Thus, he sees that beings are expanded everywhere. Those with the vision of eternity can see that the soul is transcendental, eternal, and beyond the modes of nature.

"Despite contact with the material body, O Arjuna, the soul neither does anything nor is entangled.." (Bhagavad Gita)

The Upnishads or the Hindu philosophical texts describe the Universal Self as Sat Chit Anand Translated literally in English as Truth, Consciousness, and Bliss, Sat Chit Anand describes the true nature of the Self.

Also, in an empirical study done by the authors(Sharma et al, 2020), it was found that six factors together significantly mediate between role stress and Burnout and these factors constitute the spiritual intelligence of managers.

1. Blissful Consciousness: Blissful Consciousness is also described in the Vedantic tradition as Sat Chit Anand and emerges as the most important element of SI. This implies that one is aware of the eternal truth that there is only one consciousness and that all individuals are the reflection of that consciousness and that this consciousness is a state of inner happiness. Hence, when a person becomes self-aware of mental processes and achieves a state of extreme happiness, it can be understood as blissful consciousness. People with this quality remain in a state of bliss and derive joy from all actions. As these individuals are aware of the inner self, they are also inwardly directed and utilize their inner resources. These individuals remain in a state of connectedness to the universe as a whole and its parts. In decision-making, spiritually intelligent people rely on these connections and are therefore likely to be creative and joyful.

People with blissful consciousness appreciate the sensuality and beauty of daily life, enhance effectiveness through individual connections and receptivity to others, listen to gut feeling or intuition in making important choices, mindful of their body's five senses during daily tasks, look for and try to discover their blind spots, goals and purpose extend beyond the material world and bring a feeling of joy to their activities.

2. Mindfulness: The second important constituent element of SI is again best described in Sanskrit as "Stith Pragya." Translated, Stith Pragya means Steady or situated or unmoved consciousness/ Steady Wisdom. This factor refers to mindfulness qualities that enable a person to remain in the present moment without judgment with total acceptance of reality. Mindfulness is an essential and integral element of equanimity as one can-not attain a state of situated consciousness without being present in the moment.

Such individuals do not think about the future or past and just concentrate on the present moment, they know how to just be themselves while interacting with others. They are connected with nature in daily life. They do not get upset when things go wrong. The following are the items that represent mindfulness.

3. Freedom: Freedom is the third important constituent element of SI that emerges from this study. A spiritually intelligent person is free. He does not operate in a box and is not bound by any conventions. A spiritually intelligent person is so free from the chains of his ego that he merges in the ordinary and does not consider himself separate from the rest of the world.

4. Purpose: The fourth-factor Purpose as a constituent element of SI indicates leading a life with a specific purpose or meaning that is in alignment with the larger integral whole or the ultimate reality. The purpose of life is an answer to the "why" question and it provides meaning to one's existence. Life without purpose is like a shipping vessel without navigation. A very important factor in the entire scheme of things it differentiates a person moving steadily in one direction of fulfillment from another who is just floating directionless.

5. Compassion: The fifth factor refers to compassion. Translated as "Karuna" in Sanskrit, it is a very basis of coexistence with the due realization that the other is a reflection of us. Empathy is an integral part of compassion and allows a person to project into the other to see the situation as they would see it. A compassionate person is always eager to help others and takes his decisions keeping the interest of others in mind. Such people are kind and bring a lot of positivity to the environment.

6. Daily Practice: The sixth and final constituent factor of SI is Daily Practice. A spiritually Intelligent individual has a daily and weekly time set aside for self - reflection and rejuvenation. Indian traditional text strongly recommends the practice of self-reflection, meditation and prayer to experience. Daily practice can be highly instrumental in converting Spiritual Intelligence from an intellectual pursuit to an experience that enables a person to achieve fulfillment and peace. 


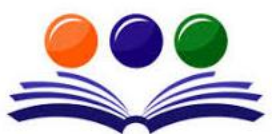

GRAND ACADEMIC PORTAL RESEARCH JOURNALS

\section{CONCLUSION}

Literature review leads us to conclude that one can lead a more content life and be a blissful leader by applying a set of principles derived from spirituality in the form of Spiritual Intelligence and hence, reduce the impact of stress in the form of burnout.

\section{REFERENCES}

[1] Anju Sharma and D M Pestonjee, A Study on Spiritual Intelligence in Leadership to Manage Role Stress and Executive Burn Out, International Journal of Management, 11(10),2020, pp 1344-1357.

[2] Burnes, Theodore R., et al. "American Counseling Association: Competencies for counseling with transgender clients." Journal of LGBT Issues in Counseling 4.3-4 (2010): 135-159.

[3] Goleman, D. (1996). Emotional Intelligence. Why it can matter more than IQ. Learning, 24(6), 49-50.

[4] Horak, Joseph J., et al. "Deconstructing God in relation to the reconstruction of self." The therapist's notebook for integrating spirituality in counseling II: More homework, handouts, and activities for use in psychotherapy (2006): 217-222.

[5] John Macquarrie, Existentialism, Westminister, 1972

[6] Kahill, Sophia. "Symptoms of professional burnout: A review of the empirical evidence." Canadian Psychology/Psychologie canadienne 29.3 (1988): 284.

[7] Maslach, Christina, et al. Maslach Burnout Inventory: Manual. Mind Garden, 2018.

[8] Maxon, Rebecca. "Stress in the Workplace: A Costly Epidemic", Summer 1999 FDU Magazine(1999)

[9] Nordin, Robert, and Jimmy Fredin. "Organizational role stress: a case study in the Swedish public sector." (2015).

[10] Olson, Kristine, et al. "Cross-sectional survey of workplace stressors associated with physician burnout measured by the Mini-Z and the Maslach Burnout Inventory." Stress and Health 35.2 (2019): 157-175.

[11] Pareek, Udai, and T. V. Rao. "Handbook for Trainees in Educational Management." Chapter One 2 (1981): 9.

[12] Robbins, S. P. (2003). Organizational Behavior (9th Ed.)New York: Prentice Hall.

[13] Robert A. Emmons (2000) Is Spirituality an Intelligence? Motivation, Cognition, and the Psychology of Ultimate Concern, The International Journal for the Psychology of Religion, 10:1, 326, DOI: 10.1207/S15327582IJPR1001_2

[14] Seshadri, D. V. R., and Arabinda Tripathy. "Innovation through intrapreneurship: The road less travelled." Vikalpa 31.1 (2006): 17-30.

[15] Sharma, Radha. (2007). Indian Model of Executive Burnout. Vikalpa. 32. 23-38. $10.1177 / 0256090920070203$.

[16] Srivastav, Avinash Kumar. "Coping with stress in organisational roles." Indian Journal of Industrial Relations 42.1 (2006): 110-128.

[17] Tripathy MM. Burnout Stress Syndrome in Managers: (A STUDY IN A Manufacturing Industry). Management and Labour Studies. 2002;27(2):89-111. doi:10.1177/0258042X0202700203

[18] "Srimad Bhagwad Gita" 